\title{
Effects of semantic cues in dichoptic presentation
}

\author{
SANDRA LEMA-STERN \\ Northwestern University, Evanston, Illinois 60201 \\ and \\ RICHARD L. GOTTWALD \\ Indiana University at South Bend, South Bend, Indiana 46615
}

\begin{abstract}
Three experiments were performed to determine the effects of semantic cues on the resolution of words presented dichoptically. In all experiments, the cued words were reported more often than the noncued words $(p<.001)$. Some "educated guessing" (responses based on the cue plus some stimulus information) was observed, but the cues had an effect above and beyond the guessing rate. Latencies were affected by whether the response was related to the cue and were unaffected by whether the cue was related to one of the stimulus words. A recursive model, consistent with the data, was briefly described.
\end{abstract}

When two different stimuli are presented separately, one to each eye, observers often report that one stimulus is predominant. One important factor that influences the perceptual resolution of these stimuli is their meaningful content.

A number of investigators have demonstrated that experience may determine stimulus dominance in dichoptic presentation. Engle (1956) presented normal and inverted photographs and found that the more familiar normal photograph was usually perceived. Bagby (1957) presented Mexican and American scenes to Mexican and American subjects and found that the scene from the subject's own culture was dominant. Toch and Schulte (1961) presented violent and nonviolent scenes to subjects who had undergone police training, subjects who were just beginning police training, and college students. They found that the subjects who had undergone police training perceived violent scenes more than the other groups.

The effects of semantic cues upon dichoptic presentation in word perception have also been investigated, but the results are mixed. Rommetveit and his associates (Rommetveit \& Blakar, 1973; Rommetveit, Toch, \& Svendsen, 1968a, 1968b) presented pairs of words differing on one letter (e.g., hell/tell) with a cue related to one of the words (devil) and found that subjects generally perceived the cued word. However, Howard

These experiments were done as independent undergraduate research projects at Indiana University at South Bend by the senior author under the direction of the junior author. Requests for reprints should be sent to Sandra Lema-Stern at Northwestern University, Department of Psychology, Cresap Neuroscience Laboratory, 2021 Sheridan Road, Evanston, Illinois 60201 . The authors would like to thank Victoria Green for assistance in the preparation of this report and Renee $G$. Rabinowitz for helpful comments on the manuscript.
(1975) found that semantic cues did not affect the resolution of dichoptic stimuli. He presented pairs of words differing on one letter (bat/bag) with either a direct cue (t) or a semantic cue (ball). He found that the direct cues had a strong effect on perceptual resolution, but the semantic cues had no effect. He suggested that the results of Rommetveit et al. (1968a) may have been due to response bias. Since only one letter differed in the binocular pairs, subjects could have been making "educated guesses" on the basis of the shared letters and the semantic cues. On the other hand, Rommetveit and his associates found that the strength of the cuing effect is related to the type of semantic cue and the time between the presentation of the cue and the presentation of the rivalry pair. It is quite possible that Howard (1975) used a type of cue and/or time interval that produced a particularly weak effect.

The present study was designed to examine the effects of verbal cues that provide information about the semantic class of one word in dichoptic presentation. In addition, an attempt was made to assess response bias produced by educated guessing as described above.

\section{EXPERIMENT 1}

\section{Method}

Subjects. Sixteen subjects were drawn from the introductory psychology pool at Indiana University at South Bend. The subjects received class credit for participating in the experiment.

Apparatus. A two-field Gerbrands Harvard Tachistoscope (T-2B-1) was used for stimulus presentation. Linear polarizers were used to separate the fields so that one was presented to each eye.

Stimuli consisted of 20 pairs of three- or four-letter words typed in uppercase on $5 \times 7 \mathrm{~cm}$ transparencies and mounted on white cards. Each stimulus word subtended approximately 
$1 / 3 \times 1 \mathrm{deg}$ visual angle. Each pair of words differed on only one letter. Ten pairs differed on the first letter and 10 differed on middle or last letter.

Procedure. Compensations were made for phenomenal brightness by adjusting illumination. Prior to making the adjustments, the subject was told that the tachistoscope was being adjusted to his vision. A nonsense syllable was presented in each field, and the subject was asked to report what he saw. Illumination was then reduced in the dominant field until the subject reported that the two syllables seemed equally clear.

The 10 pairs of words were presented to each subject in a random order. Before each trial, the subject was given a cue for the semantic class of one of the words. The cue consisted of the experimenter saying "The word you are going to see may be in some way related to ...," followed by one or more words related to one of the stimuli. For example, the word PLUM was cued by the word "fruit," the word PLUG was cued by the words "electrical devices," and so on. Each field was cued 10 times, and the selection of cued field was random. The subjects were matched so that if one field was cued for a particular word pair for one subject, the other field would be cued for that pair for the next subject. After the cue was given, the stimuli were presented. Each pair of words flashed on and off with an exposure time of $30 \mathrm{msec}$, with $90 \mathrm{msec}$ between exposures until the subject responded. Subjects were told to say the first word they saw as soon as they saw it. If a subject reported seeing two words, he was asked which word was seen first and which one seemed predominant. After the 20 trials were completed, subjects were asked if the words seemed clear, if they ever saw two words, and if they tried to make use of the cues.

\section{Results and Discussion}

The subjects' responses were put into three categories: cued word, noncued presented word, and other responses. The mean percentages of responses in each category are shown in Table 1 . The cued words were reported more than the noncued words $[\mathrm{t}(15)=16.5$, $\mathrm{p}<.001]$. In fact, all of the 16 subjects reported the cued words at least $60 \%$ of the time. Almost all of the words in the "other" category were clearly related to the cue and included one or more letters that had been presented. For example, when ROAD and TOAD were presented, with the cue "transportation," one subject responded "train." Most subjects reported that they saw the words clearly. Only four of the subjects noticed that two words had been presented. Most subjects reported that they used the cues on some but not all of the trials. There were no clear relationships between the subjects' comments and their responses.

Table 1

Mean Percentage of Responses in Each Category for Related and Unrelated Cues

\begin{tabular}{clccc}
\hline & & \multicolumn{3}{c}{ Type of Response } \\
\cline { 3 - 5 } $\begin{array}{c}\text { Experi- } \\
\text { ment }\end{array}$ & $\begin{array}{c}\text { Cue } \\
\text { Type }\end{array}$ & $\begin{array}{c}\text { Cued } \\
\text { Word }\end{array}$ & $\begin{array}{c}\text { Noncued } \\
\text { Presented } \\
\text { Word }\end{array}$ & Other \\
\hline \multirow{2}{*}{1} & Related & 81.9 & 11.2 & 6.9 \\
2 & Related & 69.6 & 23.7 & 6.7 \\
2 & Unrelated & 16.2 & 75.0 & 8.8 \\
& Related & 71.3 & 20.4 & 8.3 \\
& Unrelated & 17.1 & 72.9 & 10.0 \\
\hline
\end{tabular}

These results indicate that the cues affected the subjects' responses. It is not clear, however, whether the cues affected what the subjects saw or whether the cues simply produced a response bias so that the subjects could guess correctly on the basis of the cue and a few correctly perceived letters. Experiment 2 addressed this point by presenting cues that were not related to either of the presented words.

\section{EXPERIMENT 2}

\section{Method}

Subjects. Twenty subjects were drawn from the same pool as in Experiment 1.

Apparatus. The apparatus was the same as in Experiment 1. The stimuli consisted of 24 triads of three- or four-letter words. The words within a triad differed on one letter, with eight triads differing on the first letter, eight differing on a middle letter, and eight differing on the last letter.

Procedure. The procedure was similar to that of Experiment 1 except that on one-half of the trials the cue was unrelated to either of the presented words and on the remaining trials the cue was related to one of the words. Four conditions were arranged for each triad. In the first condition, two of the words were presented with a cue related to one of the words. In the second condition, the same cue was used but the related word was replaced by the third word in the triad. The third and fourth conditions were similar to the first and second except that the cue was related to the other presented word. For example, consider the triad NAIL, HAIL, and JAIL. In the first condition, NAIL and HAIL were presented and the cue was "carpentry." In the second condition, JAIL and HAIL were presented with the same cue. In the third condition, NAIL and HAIL were presented and the cue was "weather." In the fourth condition, NAIL and JAIL were presented with "weather." This counterbalancing was done to estimate how often subjects could guess a cued word if given the cue and several letters. The stimuli were presented in a random order, and conditions were counterbalanced across subjects.

\section{Results and Discussion}

The responses were divided into the same three categories as in Experiment 1. Table 1 shows the mean percentage of responses in each category for conditions in which the cue was related to a presented word and for conditions in which the cue was unrelated. When the cue was related to a presented word, subjects usually reported the cued word, but when the cue was unrelated subjects usually reported one of the presented words [each $t(19)>6.0, p<.001]$. The number of times that the cued word was reported, given that the cue was related, was substantially lower than in Experiment 1 $[\mathrm{t}(34)=2.575, \mathrm{p}<.05]$. This suggests that subjects were making educated guesses in Experiment 1 and that the presence of the unrelated cues in Experiment 2 reduced the frequency of guessing. However, it still appears that some educated guessing occurred, because $16.2 \%$ of the time the cued word was reported when that word had not been presented. This $16.2 \%$ may be used as an estimate of the guessing rate because subjects were unaware of the relevance of the cue. Correcting the percentage of cued word responses with related 
cues by subtracting this estimate reduces the percentage of cued word responses with related cues to $53.4 \%$. However, this corrected percentage is still greater than the percentage of responses for the noncued presented word $[t(19)=5.09, \mathrm{p}<.001]$. (The statistical comparison involved subtracting the number of cued responses with unrelated cues from the number of cued responses with related cues for each subject and comparing this result with the number of responses that were noncued presented words.)

These results suggest that educated guessing does occur. However, the semantic cues seem to have an effect above and beyond the effect of this guessing. In Experiment 2, it seemed that subjects were responding faster when the cues were related. Experiment 3 was designed to investigate these differences in latency.

\section{EXPERIMENT 3}

\section{Method}

Subjects. Twenty subjects were drawn from the same pool as in Experiments 1 and 2.

Apparatus and Procedure. The apparatus and stimuli were the same as in Experiment 2. The procedure was similar to that of Experiment 2, except that the subject was given a switch that controlled the tachistoscope and the tachistoscope flashed once for $30 \mathrm{msec}$ per switch closure rather than blinking on and off. The subject was told that he could observe as many flashes as he wished, but that he should respond as soon as he saw a word.

\section{Results and Discussion}

The responses were categorized in the same manner as in Experiment 2 and are summarized in Table 1. The distribution of responses is very similar to the distribution in Experiment 2, so the change in method had no effect. Again, with related cues, subjects usually responded with the cued words and with unrelated cues, subjects usually responded with one of the presented words [each $t(19)>5.8, p<.001]$. The estimated degree of educated guessing was about the same as in Experiment 1. This estimate reduced the percentage that the cued word was reported when the cue was related to 54.2 , but this corrected figure was still greater than the number of times the noncued word was reported $[t(19)=4.33, p<.01]$.

Table 2 shows the mean number of exposures prior to each type of response. Statistical analysis of these data was complicated by the fact that not every subject had a response in each category. Comparisons involved $t$ tests between pairs of categories using only those subjects with a response in each category. The cued words were given earlier than the noncued words [for related cues, $\mathrm{t}(17)=3.73, \mathrm{p}<.01$; for unrelated cues, $t(14)=2.27, p<.05]$. The cued words tended to be given earlier than the responses in the "other" category, although only one comparison was significant [for related cues, $\mathrm{t}(10)=3.14, \mathrm{p}<.05$; for unrelated cues, $t(12)=1.79, p<.10]$. There were no significant differences between similar categories due to type of cue. To emphasize this lack of difference, it is worth noting
Table 2

Mean Number of Exposures for Each Category (Experiment 3)

\begin{tabular}{|c|c|c|c|c|c|c|}
\hline \multirow{3}{*}{$\begin{array}{l}\text { Type of } \\
\text { Cue }\end{array}$} & \multicolumn{6}{|c|}{ Type of Response } \\
\hline & \multicolumn{2}{|c|}{$\begin{array}{l}\text { Cued } \\
\text { Word }\end{array}$} & \multicolumn{2}{|c|}{$\begin{array}{c}\text { Noncued } \\
\text { Presented } \\
\text { Word } \\
\end{array}$} & \multicolumn{2}{|c|}{ Other } \\
\hline & Mean & $\mathbf{N}$ & Mean & $\mathbf{N}$ & Mean & $\mathrm{N}$ \\
\hline $\begin{array}{l}\text { Related } \\
\text { Unrelated }\end{array}$ & $\begin{array}{l}3.02 \\
3.59\end{array}$ & $\begin{array}{l}20 \\
15\end{array}$ & $\begin{array}{l}4.53 \\
4.61\end{array}$ & $\begin{array}{l}18 \\
20\end{array}$ & $\begin{array}{l}4.21 \\
6.64\end{array}$ & $\begin{array}{l}11 \\
14\end{array}$ \\
\hline
\end{tabular}

Note $-N$ refers to the number of subjects who had a response in the category.

that, of the 15 subjects who had a response in each of the cued categories, 7 responded faster with related cues, 7 responded faster with unrelated cues, and there was 1 tie. The difference between the means of these categories is due to one disparate score. If the subject with the disparate score is deleted, the means become 2.90 and 2.91 for related and unrelated cues, respectively. There were 18 subjects with a response in both noncued presented categories; 9 responded faster with related cues, and 9 responded faster with unrelated cues. There were only eight in both "other" categories; three responded faster with related cues, and five responded faster with unrelated cues.

In summary, the results of Experiment 3 are consistent with those of Experiment 2 in terms of the words reported. When related cues were used, subjects usually responded with the cued word, but when unrelated cues were used, subjects usually responded with one of the words presented. However, the number of exposures required was affected only by whether the response given was cued and was unaffected by the relevance of the cue.

\section{GENERAL DISCUSSION}

The results of the present experiments demonstrate that semantic cues affect perception in dichoptic presentation. This finding confirms the results obtained by Rommetveit and his associates (Rommetveit \& Blakar, 1973; Rommetveit et al., 1968a, 1968b). It is not clear why Howard (1975) failed to obtain similar results. One possible reason for this discrepancy, mentioned above, is that Howard (1975) may have chosen a type of cue and/or time interval between cue and stimulus presentation that produced a particularly weak effect.

The present results also indicate that educated guessing does occur, although it is clear that the cues have an effect above and beyond this guessing. The use of unrelated cues in the last two experiments reduced the percentage of responses related to the cues as compared to the first experiment. It is likely that this reduction occurred because subjects adopted a more stringent criterion for guessing when the cues were not always relevant. A very stringent criterion for guessing could have produced the discrepant results obtained by Howard (1975). Neither Howard nor Rommetveit and his associates used unrelated cues, so it is not possible to estimate the guessing rates in their studies. Since educated guessing did occur in the present study, it would seem worthwhile to include unrelated cues in future studies, when feasible, so that the guessing rate can be estimated.

The use of unrelated cues in the present studies also indicates 
that it is highly unlikely that subjects were responding to degraded stimuli. Since one letter in each of the paired words differed, it might be argued that the subjects filled in the degraded letter with the letter from the word that was cued. This, however, was not the case. If the cued word was not present (the unrelated cue condition), subjects tended not to report it.

The latency data from Experiment 3 are slightly puzzling. The latencies were only affected by whether the response was cued and were not affected by the relevance of the cue. This result would suggest that subjects were only responding on the basis of the cues. However, when the cues were unrelated, subjects usually responded with one of the stimuli, so they were clearly attending to the stimuli. Furthermore, as pointed out above, the subjects seemed to be using some stimulus information even in their educated guessing. These results are consistent with a recursive process such as that suggested by Bruner (1957). It is possible that subjects used the cues plus some stimulus information to tentatively identify the stimulus and then double-checked to confirm this identification. If the identification was confirmed, they gave it as a response, and if it was infirmed they rejected it and searched for more information. Since subjects did report cued words that were not presented, the confirmation would have to be probabilistic. Following this model, if subjects responded on the basis of the cue, they responded faster. However, if the cue was unrelated, the identification usually failed the confirmation and was rejected. Thus, when the cues were unrelated, subjects usually responded with a presented word but the latency was longer. Since the confirmation is probabilistic, the stringency of this stage could be varied, and this could be the mechanism for setting the guessing criterion.

This is a very cognitive explanation and it should be noted that the subjects did not seem aware of any inferential process. According to verbal report, most subjects were unaware that two words were presented and usually said that they simply saw the word that they reported.

\section{REFERENCES}

BAGBY, J. A cross-cultural study of perceptual predominance in binocular rivalry. Journal of Abnormal and Social Psychology, 1957, 54, 331-334.

Bruner, J. S. On perceptual readiness. Psychological Review, 1957, 64, 123-152.

ENGEL, E. The role of content in binocular resolution. American Journal of Psychology, 1956, 69, 87-91.

HowARD, R. B. The influence of direct and indirect semantic contexts on binocular-rivalry resolution. Bulletin of the Psychonomic Society, 1975, 5, 213-214.

RommetveIT, R., \& BLAKAR, R. M. Induced semantic-associative states and resolution on binocular-rivalry conflicts between letters. Scandinavian Journal of Psychology, 1973, 14, 185-194.

Rommetveit, R., Toch, H., \& Svendsen, D. Effects of contingency and contrast contexts on the cognition of words. Scandinavian Journal of Psychology, 1968, 9, 138-144. (a)

Rommetveit, R., Toch, H., \& Svendsen, D. Semantic, syntactic, and associative context effects in a stereoscopic rivalry situation. Scandinavian Journal of Psychology, 1968, 9, 145-149. (b)

Tосн, H. H., \& Schulte, R. Readiness to perceive violence as a result of police training. British Journal of Psychology, 1961, 52, 389-393.

(Received for publication January 15, 1979.) 